\title{
Modern technologies of construction of residential and office buildings with removable formwork
}

\author{
Vladimir Efimov ${ }^{1, *}$, Muhammet Fakhratov ${ }^{1}$, Vitaliy Chulkov ${ }^{1}$, and Denis Pogodin $^{1}$ \\ ${ }^{1}$ Moscow State University of Civil Engineering, Yaroslavskoe shosse, 26, Moscow, 129337, Russia
}

\begin{abstract}
The Plastbau and Plastbau-3 systems are mainly used in construction of residential and office buildings. These technologies can be used for construction at low temperatures. The design of wall formwork elements includes the outer and inner layers of polystyrene foam fastened together at the $200 \mathrm{~mm}$ distance with a frame made of 3-8 $\mathrm{mm}$ reinforcing bars. The systems' thermal insulation capacity is very high and varies depending on the thickness of polystyrene foam walls. Insulation slabs of the Plastbau-3 formwork panels are made of first class polystyrene foam with a density of $30 \mathrm{~kg} / \mathrm{m} 3$ and an almost unlimited working life is guaranteed. High efficiency and energy conservation rate embedded in this construction technology and its elements allow to construct high-quality housing at a low cost. Currently, the Plastbau-3 technology is used at construction sites in Moscow, St. Petersburg, Saratov, Orenburg, and other cities.
\end{abstract}

\section{Introduction}

It has been a long time since construction materials production industry in Russia last saw a modernisation. In Russian regions, key production assets are accumulated at large enterprises (integrated house-building factories, reinforced concrete structures plants, concrete products plants), many of them not operating at full capacity. They issue highpriced products, which impedes the implementation of federal and regional housing programs.

Foreign experts believe that the disadvantages of mass apartment building development include: poor inter-floor and inter-apartment sound insulation, which reduces the comfort of living; in spring and autumn; indoor temperature largely depends on the weather outdoor; considerable utility costs

The Plastbau technology allows to reduce the cost and time of construction, improve the comfort of housing (reduce the level of noise, improve the thermal performance, provide an opportunity for individual redesign), significantly reduce the operating costs for the built houses.

Key advantages of the technology:

- light weight of the elements (the walls measure $120 \times 40 \times 300 \mathrm{~cm}$, their weight is up to

* Corresponding author: efimov1234@mail.ru 
$21 \mathrm{~kg}$; the floors measure $60 \times 30 \times 600 \mathrm{~cm}$, their weight is up to $24 \mathrm{~kg}$ ) allows to construct cast-in-place reinforced concrete buildings without any heavy lifting devices on the construction site (Fig.1), the lighter weight of buildings allows the use of existing foundations and of buildings under reconstruction and make additions;

- minimal size of the construction site in high-density development areas;

- high thermal insulation and waterproofing capacities allow concreting at sub-zero temperatures without heating;

- thermal insulation properties are equally high in cold, hot, and humid climates;

- sound insulation ranges from -50 to $-56 \mathrm{~dB}$;

- high seismic resistance of buildings (up to 9 points on the Richter scale);

- an opportunity to construct more than 1.5 times higher buildings (the "wet processes" are excluded).

- residential and industrial construction can be carried out in permafrost, with the framework raised above the ground level, in remote regions of Russian North as well as Western and Eastern Siberia;

- construction can be carried out in steppe and desert areas where there is a shortage of timber;

- single-family houses can be built by 2-4 people;

- the technology can be applied for the construction of low-rise motels and service buildings (food, recreation);

- the technology can be applied for the construction of healthcare facilities, tourist centres, educational institutions, and related structures;

- an opportunity to add more storeys to existing buildings without the need to strengthen their foundations and walls using the existing strength reserve.

\section{Materials and methods}

Plastbau load-bearing structures are a cast-in-place reinforced concrete spatial system consisting of reinforced concrete longitudinal and cross walls, ribbed floors, and girt strips connecting walls and floor slabs.

The thickness of the external polystyrene foam elements varies from 5 to $25 \mathrm{~cm}$ and depends on climate conditions. 60 to $120 \mathrm{~cm}$ wide and one floor high polystyrene foam elements are used for walls. 6 to $12 \mathrm{~m}$ long, 60 or $120 \mathrm{~cm}$ wide and 6 to $12 \mathrm{~cm}$ thick polystyrene foam elements are used for floors and surfaces.

To ensure the necessary fire protection Plastbau elements can be covered with a layer of plaster or walls can be lined with gypsum fiber boards or gypsum plaster boards.

Reliability and safety indices of the Plastbau technology are established on the basis of: tests of the load-bearing ability of the system and its elements performed by VNIIzhelezobeton (All-Russia Scientific Research Institute of Reinforced Concrete) on full-scale fragments of a floor, a wall, and a five-storey residential building;

- fire tests performed by TSNIISK (Research Institute of Building Constructions) on full-scale fragments of a wall and a floor of a five-storey residential building; $\neg$

- sanitary and chemical tests performed by the Erisman Federal Scientific Centre of Hygiene on a full-scale fragment of a wall panel with a medium-thickness layer of polystyrene foam;

- control computations of the effective resistance to heat transfer in blank areas of external walls, performed in the Federal Centre for Standardisation;

- control computations performed by Moscow Research and Design Institute of Typology and Experimental Design to determine the level of sound insulation of internal cladding structures;

- fire resistance test report No. 78861/1243PR by Istituto Giordano S.p.A. (Polytechnic 
Research Centre) in Bellaria, Italy.

Comparative thermal properties of materials and structures (the first number denotes the density of a material $(\mathrm{kg} / \mathrm{m} 3)$ and the second one denotes the thickness of the thermal insulation layer required to ensure a heat transfer resistance level that equals $1 \mathrm{~W} /\left(\mathrm{m}^{\circ} \mathrm{C}\right)$ : reinforced concrete $2500-169 \mathrm{~cm}$; aerated concrete and foam concrete $600-14 \mathrm{~cm}$; common brick with a cement-and-sand grout $1800-56 \mathrm{~cm}$; calcium silicate brick with a cement-and-sand solution $1800-70 \mathrm{~cm}$; slag brick with a cement-and-sand solution 1500 $52 \mathrm{~cm}$; expanded clay gravel $800-18 \mathrm{~cm}$; crushed blast furnace slag, crushed expanded blast furnace slag and agloporite crushed stone $600-15 \mathrm{~cm}$; pine and spruce against the grain $500-9 \mathrm{~cm}$; fibreboard and particle board $800-13 \mathrm{~cm}$; of mineral wool quilt mat with a synthetic binder $125-5.6 \mathrm{~cm}$; soft, semi-rigid and rigid mineral wool boards with a synthetic and bitumen binder $200-7 \mathrm{~cm}$; PSB-S-25 polystyrene foam boards $25-3.9 \mathrm{~cm}$

\section{Results}

Plastbau-3 wall: two high-density polystyrene foam panels connected with steel structures, the distance between the panels may vary. After concreting, these structures serve as a reinforcement cage. $120 \mathrm{~cm}$ wide (or narrower) panels with a projected height are installed end-to-end, thus creating a rigid structure that eliminates the need for a wall plate system and is completely ready for concreting. No height restrictions apply to Plastbau-3 walls. $\neg$ In addition to plaster, which is a typical finishing material, such walls can be finished with polystyrene foam, plasterboard, or gypsum fiber board that has a high level of acoustic absorption $\mathrm{Rw}=53 \mathrm{~dB}$ and good fire resistance $\mathrm{RAL} 180$.

The outer side of the structure is covered with an extra-strong propylene foam net, then with additive-containing solutions compatible with polystyrene foam.

Plastbau-3 formwork elements are installed manually, the installation is facilitated by the galvanized sheet guiding channels that are pre-attached to the floor slab under a $50 \mathrm{~mm}$ thick inner polystyrene foam panel.A similar profile attached to the upper edge of the panel is used to ensure a perfectly smooth installation of wall elements. $\neg$ After concreting, the upper channel can be removed and reused.

A standard Plastbau-3 panel is $120 \mathrm{~cm}$ wide, $285 \mathrm{~cm}$ high to the floor pivot and $315 \mathrm{~cm}$ high to the concrete safety edge of the girt, it weighs $22 \mathrm{~kg}$; thus, two people can easily carry and install it without using any lifting devices.

Very little working time is required for unloading panels from the truck, stacking them, calibrating guide rails, installing the panels, fastening them together, attaching them to connection bars and subsequently adjusting them with a plumb line using props with special clamps. Judging by the experience on numerous construction sites and in a variety of working conditions, total installation time is 3-8 $\mathrm{m} 2 /$ hour.

Linking the panels together is facilitated by channels on both their internal and external surfaces. The panels themselves are attached to the connection bars, and they are fastened together with ordinary metal wire (tools: pliers and a coil of metal wire).

Due to its rigidity, Plastbau-3 panel does not need any additional formwork. As a rule, one prop with a special leveling clamp is sufficient for every two to three panels, the only function of these props is to plumb the panel.

To create the formwork for the girt and ensure the continuity of the insulation on the facade at the same time, perimeter wall panels are manufactured at the factory in such a way that the outer panel is higher than the inner one and reaches the level of a finished floor slab.Thanks to the spatial metal frame embedded in the panel, no additional formwork is needed in the area.

The reinforcement bars inside the spatial frame of the panel are $8 \mathrm{~mm}$ in diameter, there are 10 bars in each linear meter. They are welded one opposite the other at intervals of 20 
$\mathrm{cm}$; there are diagonal and horizontal reinforcing bars with a diameter of $3 \mathrm{~mm}$ and horizontally lashed strut reinforcement bars with a diameter of $5 \mathrm{~mm}$. This arrangement of reinforcement bars and their number are taken into account in the design calculation of the wall. Vertical bars of the spatial frame are made of welded cold-drawn steel with improved adhesion capacity and permissible pressure of $2600 \mathrm{~kg} / \mathrm{cm} 2(255 \mathrm{~N} / \mathrm{mm} 2)$. Due to their special position the bars are completely immersed in a layer of concrete (the thickness of the protective layer is $2 \mathrm{~cm}$ ), which corresponds to all applicable standards.

Screw caps made of extra-strong polypropylene hold together polystyrene foam slabs with transverse connecting fittings $(5 \mathrm{~mm}$ in diameter) welded from the inside and having male thread. They are designed in such a way as to withstand the pressure of concrete and ensure continuous pouring of up to $3 \mathrm{~m}$ of concrete in one go. Concreting is carried out by traditional methods; it is necessary to ensure that the concrete jet is directed strictly inside the panel. The fluidity level of the concrete must meet the standard (precipitation = 3.4).The granulometric curve for fillers should be below 20 .

Concrete with the fluidity $=\mathrm{S} 4$ poured into the Plastbau-3 formwork does not require vibrating. If necessary, slight vibration may be used to check the pressure on the walls. $\neg$ The control points are polypropylene plugs on the sides of the panel; they should never be sunk in polystyrene foam. Thermal insulation with polystyrene foam allows concreting even at temperatures close to zero and below; in this case, the exposed surface of the concrete should be covered.

Tests carried out by the Portland Cement Association show that concrete maturing during the required time in moisture conditions with Plastbau-3 formwork achieves a compressive strength that is more than 1.5 times higher than that of concrete released from conventional formwork after three days (Fig. 1)

Polypropylene mesh for applying plaster (it makes an integral part of the PLASTBAU-3 wall panel) is heat-welded to the caps of threaded plugs located on the outside of the panel and allows one to apply plaster of any type.

Apart from the ordinary polystyrene foam-compatible plaster, internal surfaces of walls can be covered with plasterboards or gypsum fiber boards fixed with an adhesive and screwed to plastic plugs thus ensuring the minimum guaranteed level of sound absorption. $\neg$ Since the plugs can be adjusted, the gypsum fiber boards installation process is fast, costeffective, and rational.

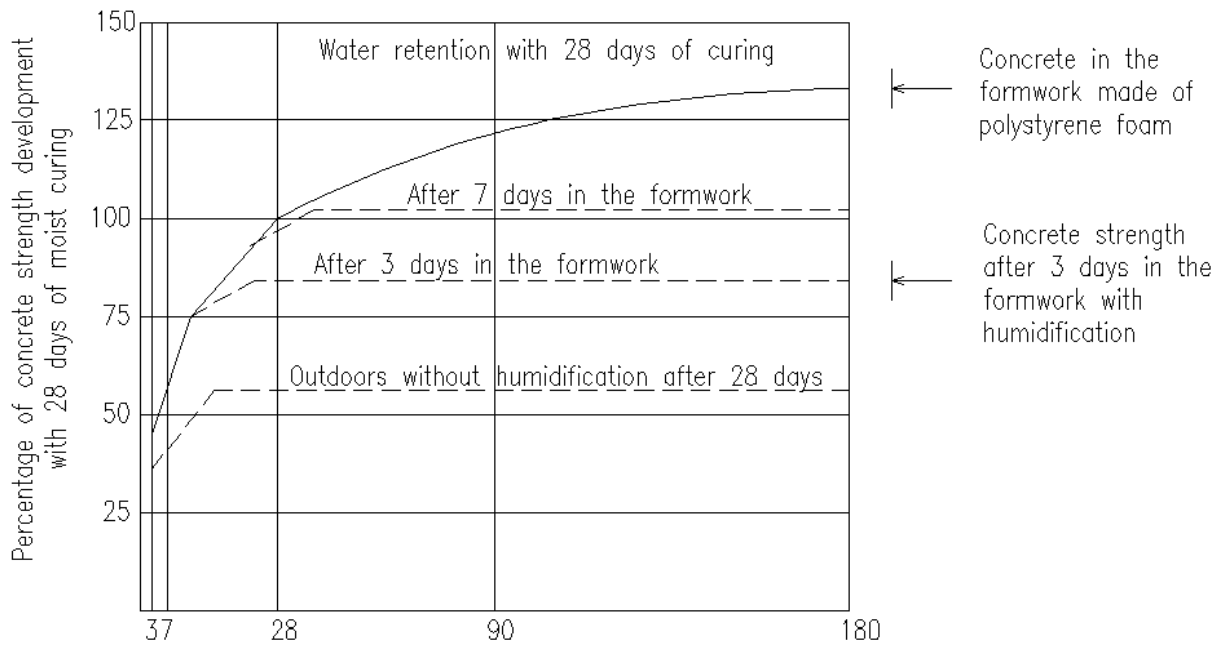

Fig.1. Results of the research conducted by Portland Cement Association

Insulation plates in the Plastbau-3 formwork panels are made of first class polystyrene 
foam with a density of $30 \mathrm{~kg} / \mathrm{m} 3$, an almost unlimited working life is guaranteed. $\neg \neg$ This is confirmed by tests carried out in the laboratory of the BA8P company that show that the polystyrene foam slabs that were covered with a layer of plaster for 35 years, have preserved their original characteristics.

The thermal insulation capacity of the polystyrene foam walls is very high and varies depending on their thickness. For example, the level of thermal insulation of a typical $5 / 15 / 5$ panel consisting of two polystyrene foam walls each $5 \mathrm{~cm}$ thick with $15 \mathrm{~cm}$ of concrete between them is such that the coefficient of thermal conductivity $\mathrm{K}=0.34 \mathrm{~W} / \mathrm{m} 2$. If the thickness of the outer polystyrene plate is $10 \mathrm{~cm}(5 / 15 / 10)$, the value of $\mathrm{K}=0.23 \mathrm{~W} / \mathrm{m} 2$.

Polystyrene foam is frequently used as fixed formwork for external walls in the cast-inplace and precast Plastbau-3 construction system. The same polystyrene products are used for partitions. During the production polystyrene foam elements are reinforced by steel frameworks for better load accommodation. Working surfaces of elements are protected with plaster solutions. $\neg \neg$ The Plastbau-3 system allows to construct buildings for various purposes (from cottages to offices) and suitable for different outdoor temperatures (within $\pm 5^{\circ} \mathrm{C}$ ). $\neg$ The floor load is up to $400 \mathrm{~kg} / \mathrm{cm} 2$; the distance between vertical load-bearing walls is $9 \mathrm{~m}$; the floor height is $2.7 \mathrm{~m}$

\section{Conclusions}

The Plastbau-3 system is very economical because it provides substantial reduction of costs of transport and lifting equipment (craneless building technology); moreover, due to the low weight of the structures, the mass of the foundations is lower as well, which brings down the cost of the zero phase of construction by 1.8 times.

Construction time is also reduced several-fold and there is a much lower labor intensity in comparison with traditional technologies. The cost of $1 \mathrm{~m} 2$ in an equipped cottage is about 30\% lower than if traditional construction methods are used.

High speed of construction (a team of four workers can build an individual house in 6 to 9 weeks). Modern construction technologies have made quantum strides recently.

A tidy construction site, prompt installation, and its versatility make Plastbau system the most practical and cost-effective solution currently offered on the market.

\section{References}

1. Guidelines on construction works using the PLASTBAU-3 fixed formwork technology. ZAO Uzlovskiy Plant of Building Structures - Tsentrgaz

2. V.O. Chulkov, M.A. Fakhratov, A.A. Kalgin Production and use of building materials (Moscow, SVR-ARGUS. 2006).

3. F. De Lillo, F. Cecconi, G. Lacorata, A. Vulpiani, EPL, 84 (2008)

4. R.Z. Rakhimov, N.S. Shelikhov Modern insulation materials. (Kazan: KSUAE, 2006)

5. V.O. Chulkov, M.A. Fakhratov, A.A. Kalgin Production and use of construction materials, products and systems: Volume 2 (Moscow, SVR-ARGUS. 2011)

6. V.O. Chulkov (ed.) Production and use of building materials, products and systems: Volume 4 - production of precast concrete structures for construction purposes. Design and reconstruction of enterprises. (Moscow, SVR-ARGUS, 2012)

7. A. A. Lapidus, M. N. Yershov Modern technologies of civil buildings reconstruction (Moscow, ASV, 2014)

8. V.O. Chulkov, R.R. Kazaryan, B.A. Levin Infographic models of anthropotechnical management. A modular course of lectures. Volume 3. (Moscow, 2017) 